\title{
Botany
}

\section{A new species of penzigioid Xylaria (Xylariaceae) from the cloud forest in eastern Mexico revealed through morphological and phylogenetic analyses}

\begin{tabular}{|c|c|}
\hline Journal: & Botany \\
\hline Manuscript ID & cjb-2019-0043.R2 \\
\hline Manuscript Type: & Article \\
\hline $\begin{array}{r}\text { Date Submitted by the } \\
\text { Author: }\end{array}$ & 04-Apr-2019 \\
\hline Complete List of Authors: & $\begin{array}{l}\text { Chacón, Santiago; Instituto de Ecologia, Red de Biodiversidad y } \\
\text { Sistemática } \\
\text { González, Dolores; Instituto de Ecologia, Red de Biodiversidad y } \\
\text { Sistemática }\end{array}$ \\
\hline Keyword: & Ascomycota, DNA sequences, Phylogeny, Taxonomy, Xylariales \\
\hline $\begin{array}{r}\text { Is the invited manuscript for } \\
\text { consideration in a Special } \\
\text { Issue? : }\end{array}$ & Not applicable (regular submission) \\
\hline
\end{tabular}

SCHOLARONE Manuscripts 
A new species of penzigioid Xylaria (Xylariaceae) from the cloud forest in eastern Mexico revealed through morphological and phylogenetic analyses

\author{
Santiago Chacón and Dolores González
}

Instituto de Ecología, A.C., Red de Biodiversidad y Sistemática, Carretera Antigua a

Coatepec No. 351, El Haya, Xalapa, Veracruz, México. 91070

santiago.chacon@inecol.mx

dolores.gonzalez@inecol.mx

Corresponding author: Dolores González, Instituto de Ecología, A.C., Red de Biodiversidad y

Sistemática, Carretera Antigua a Coatepec No. 351, El Haya, Xalapa, Veracruz, México.

91070, phone: +52(228)842 1800 Ext.3108, e-mail: dolores.gonzalez@inecol.mx 


\begin{abstract}
Xylaria subtropicalis, a species new to science, was collected from a montane cloud forest in eastern Mexico. It is described and illustrated, based on detailed macro- and microscopic morphological characteristics, habitat, and DNA sequence data. The distinctive morphological differences between $X$. subtropicalis and other Xylaria species include: the stromata being significantly erumpent, the size of the ascospores being $23-28 \times 13-15 \mu \mathrm{m}$, and a straight germ slit as long as the spore. To determine if this was a novel species, ITS sequences were generated and compared with 2478 sequences available for the genus from GenBank using the software USEARCH. Additionally, a phylogenetic reconstruction was performed with Parsimony Ratchet, Maximum Likelihood, and Bayesian Inference, using 122 concatenated ITS sequences, and segments from the 28S rDNA and RPB2. Sequences of this novel species form a strongly supported lineage, clearly separated from other species of Xylaria. Phylogenetic relationships indicate that there have been numerous morphological transformations within the genus.
\end{abstract}

Keywords: Ascomycota, DNA sequences, Phylogeny, Taxonomy, Xylariales 


\section{Introduction}

The montane cloud forest, known in Mexico as the "bosque mesófilo de montaña," occupies about 1\% of Mexican territory (Rzedowski 1978, 1996; Challenger 1998). This forest contains at least $10 \%$ of the vascular plants of the Mexican flora, including 762 species of trees (González-Espinosa et al. 2012). The fungal species in the cloud forest are diverse. Currently, a database of 6349 records representing 2962 fungal species from the Neotropical cloud forests has been assembled (Del Olmo-Ruiz et al. 2017). By 1993 in Mexico, 594 fungal species had been recorded from this ecosystem (Chacón and Medel 1993). Medel (2013) identified 107 species as ascomycetes, of which 69 were found in the cloud forests of Veracruz. For the genus Xylaria Hill ex Schrank, San Martín and Rogers (1995) and Medel (2007) listed 105 and 109 species, respectively, from Mexico. Veracruz contained 45 species (Medel et al. 2008), with approximately 25 species located in cloud forests.

Xylaria contains more than 300 species, which are primarily distributed around the world in tropical and subtropical regions, and is one of the genera with the greatest number of species within the family of Xylariaceae (Kirk et al. 2008). The genus Xylaria is characterized by its stromata that are usually erect, cylindrical, or clavate, sometimes sub-globose, and a height usually larger than the width. Perithecia are circumambiently embedded immediately beneath the surface, with asci having amyloid apical rings and pigmented ascospores usually with a straight, oblique, or spiral germ slit (San Martín and Rogers 1995; Ju et al. 2009). Some species of Xylaria are distinguished by their penzigioid stromata. Penzigioid species were once placed in Penzigia Sacc., but Ju and Rogers (2001) demonstrated that the type species of Penzigia (P. cranioides Sacc. \& Paol.), belongs to Xylaria. There are more than 40 penzigioid Xylaria species worldwide (Ju et al. 2012), which are characterized by sessile stromata adhered to the substrates through a narrow central connective structure (Ju et al. 2012; Tapia et al. 2017). Some penzigioid Xylaria species known from Mexico include $X$. albocinctoides Y.M. Ju, H.M. Hsieh \& J.D., X. anisopleura (Mont.) Fries, X. berteri (Mont.) 
Cooke ex J.D. Rogers and Y.-M. Ju, X. boergesenii (Ferd. \& Winge) P.F. Cannon, X. discolor (Berk. \& Broome) Y.M. Ju, H.M. Hsieh, J.D. Rogers and Jaklitsch, X. enteroleuca (J.H. Mill.) P.M.D. Martin, X. frustulosa (Berk. \& M.A. Curtis) Cooke, X. xylarioides (Speg.) Hladki \& A.I. Romero (San Martín and Rogers 1995; Tapia et al. 2017), and Penzigia conostoma (Mont.) J.H. Mill, an invalidly published name recorded by Chacón and Guzmán (1983) from Veracruz.

Morphological identification of Xylaria species is difficult since some characters are often in conflict or missing, such as cultural features, anamorphs, exceptional variations in the color, size, and sometimes shape of stromata (Rogers 1984, 1985; Tang et al. 2009). Consequently, DNA sequence data are frequently incorporated into taxonomic studies to elucidate phylogenetic relationships. Ribosomal regions such as nuclear 28S rDNA, ITS (ITS1-5.8S-ITS2), and protein-coding genes including RPB2 and ß-tubulin have been used for molecular phylogenetic studies of the Xylariaceae (Lee et al. 2000; Tang et al. 2009; Hsieh et al. 2010; U'Ren et al. 2016). These gene regions have been widely used in mycology as fungal DNA barcodes to identify unknown specimens or cultures (Stielow et al. 2015). In the present study, a new species of Xylaria from a cloud forest in central Veracruz, Mexico, is described based on morphological characters and phylogenetic analyses using sequence data.

\section{Materials and Methods}

\section{Sample collection}

Between 2011 and 2015, specimens of Xylaria with penzigioid stromata were collected from wood bark in a patch of a preserved montane cloud forest. The study area is in west Xalapa Veracruz, Mexico and had the following sampling sites: the "Santuario del Bosque de Niebla", the Botanical Garden "Francisco Javier Clavijero", and the "Molino de San Roque", each separated from the others by approximately seven kilometers. Elevation at the study area varied between 1300 and $1460 \mathrm{~m}$. The climate is mild and humid during the 
entire year, with an annual temperature between 16 and $18^{\circ} \mathrm{C}$, and total annual precipitation between 1517 and $1650 \mathrm{~mm}$. Dominant canopy tree species have temperate affinities and include species of Carpinus, Clethra, and Quercus; whereas, understory trees and shrubs have tropical affinities (Muñiz-Castro et al. 2006; Toledo-Aceves et al. 2014).

\section{Morphological studies}

Freshly collected stromata were sectioned and mounted in water or $5 \% \mathrm{KOH}$ prior to microscopic examination of structures. Melzer's iodine reagent was used to stain the ascus apical ring. Voucher specimens were deposited at the Herbarium of the Instituto de Ecologia, A.C. (XAL). Photographs of the stromata, ascospores, and asci were used to prepare a detailed description of the species.

\section{DNA extraction, PCR amplification, and sequencing}

Total genomic DNA was extracted from ten specimens of Xylaria from the cloud forest (Table 1), using the DNeasy plant and fungi mini kit (Qiagen, Valencia, California, USA). The DNA samples were amplified with specific primers and cycle conditions for ITS, partial 28S, rDNA, and gene coding for the second largest subunit of RNA polymerase II (RPB2) (Table 2). PCR reactions were carried out in a thermocycler Eppendorf Mastercycler pro S (Hamburg, Germany) in a $25 \mu \mathrm{L}$ mix containing approximately $25-50 \mathrm{ng}$ of extracted DNA, $5 \mu \mathrm{L}$ of PCR buffer $5 \times, 0.2 \mathrm{mM}$ dNTPs, $1.6 \mu \mathrm{M}$ of both the forward and reverse primers, $2 \mathrm{mM} \mathrm{MgCl}_{2}, 0.2 \mathrm{U}$ of Go Taq flexi DNA polymerase (Promega, Madison, Wisconsin, USA), and distilled water. The amplified DNA was purified prior to sequencing with the GenElute Gel extraction kit (Sigma-Aldrich, St. Louis, Missouri, USA), and sequenced using the ABI PRISM BigDye Terminator v3.1 Cycle Sequencing Kit (Applied Biosystems, Foster City, California, USA) according to the manufacturer's instructions. The PCR products were cleaned with an isopropanol precipitation and processed on an ABI 310 genetic analyzer (Applied Biosystems, Foster City, California, USA). The resulting sequences 
were edited with the BioEdit software 7.1.3.0 (Hall 1999), and initially blasted in GenBank (https://blast.ncbi.nlm.nih.gov/Blast.cgi) with blastn to assess genetic affinities.

Comparison of ITS sequences among Xylaria species

To evaluate the potential novelty of newly collected specimens of Xylaria, ITS sequences generated in this study were compared with 2478 available sequences of this genus downloaded from GenBank (retrieved March 2018). From these sequences, a database containing 2136 sequences was constructed by removing all identical or incomplete sequences, plus any sequences from other fungi. USEARCH software v10.0.240 was employed (Edgar 2010), with the 'usearch_global' option at a 90 and 95\% identity threshold for identifying the sequences that could well align with our sequences. Within this database, the 'cluster_fast' command set at a 0.9 clustering threshold was used to assemble similar sequences into clusters through multiple alignments.

\section{Phylogenetic analyses}

To determine the identity of ten collections of a novel Xylaria species, three matrices were assembled (A, B, C) with sequences downloaded from GenBank and the newly collected specimens of Xylaria. Matrices A and B contained 122 concatenated sequences of ITS (ITS15.8S-ITS2), 28S, and RPB2; however, for matrix B the highly variable ITS1 region was excluded to avoid poorly aligned regions. These matrices contained sequences primarily from studies conducted by Hsieh et al. (2010) and U'Ren et al. (2016), and included multi-gene sequence data for most Xylaria species. Nonetheless, several terminals from the $28 \mathrm{~S}$ were missing in their matrices; therefore, the third matrix $\mathrm{C}$ was constructed with 339 sequences available in GenBank, containing both ITS and 28S (including those from U'Ren et al. 2016). Alignment of the sequence data was performed using the MAFFT software v7.244, which allows for the detection of homologous segments through the iterative refinement of an initial alignment (Katoh and Standley 2013). 
Analyses of matrices A and B were performed with three methods of phylogenetic reconstruction: Parsimony ratchet (PR), Maximum Likelihood (ML), and Bayesian Phylogenetic Inference (BPI). Analyses with matrix C were conducted with PR and BPI. PR was conducted using NONA (Goloboff 1994; Nixon 1999), with 2000 iterations, holding 10 trees per iteration, with a $10 \%$ of randomly constrained nodes and gaps recorded as missing data. Statistical branch support was determined through the means of a jackknife (JK) analysis, running 1000 replicates with 10 searches per replica with MULTMAX in effect. Before the analyses with ML and BPI, we used the program PartitionFinder 2 (Lanfear et al. 2017) for selecting the best model of sequence evolution for the analyses. The commands 'unlinked' for branch length and 'all' for the model were used. Metrics for comparing partitioning schemes were the Bayesian information criterion (BIC) and the command 'all' for the search option on the five partition schemes: ITS, 28S, and one for each codon position of the RPB2. ML was performed using RAxML at Trex-online (http://www.trex.uqam.ca/index.php?action=raxml), with the default rapid hill-climbing algorithm and the GTRGAMMAI substitution model selected after analysis with PartitionFinder 2. Support values for ML were calculated simultaneously by conducting 1000 rapid bootstrap (BS) replicates, with $10 \mathrm{BS}$ searches per replicate to obtain better ML trees for each (Stamatakis 2006; Boc et al. 2012). The BPI analyses were conducted using MrBayes 3.1.2 (Huelsenbeck and Ronquist 2001; Ronquist and Huelsenbeck 2003; Altekar et al. 2004), and the model selected by PartitionFinder 2 consisted of a general time-reversible model for each partition scheme (rates $=$ invgamma, $n s t=6$ ), with unlinked parameters and variable rates for all partitions. The analyses were performed using two independent 3 to 5 million generation runs, with four chains (one cold and three hot) each, until an average standard deviation of split frequencies of 0.01 or less was reached. The trees were sampled every 100th generation along with discarded initial samples applying a "burn-in" value of $25 \%$, before calculating the majority consensus tree and posterior probabilities (PP) for clades. Poronia 
pileiformis (Berk.) Fr., Podosordaria muli J.D. Rogers, Y.M. Ju \& F. San Martin, and Podosordaria mexicana Ellis \& Holw. were used as the outgroup taxa (U'Ren et al. 2016) for rooting the tree. The trees were subsequently edited using Adobe Illustrator 16.0.0 (Adobe Systems, San Jose, CA, USA). The alignments and resulting trees are deposited in TreeBASE (TreeBASE accession: S21630). GenBank accession numbers with species names used in the analyses are included in each cladogram.

\section{Results}

\section{Comparison of ITS sequences}

Analysis of the 2136 sequences from the ITS region with the 'usearch_global' algorithm showed that Xylaria primorskensis Y.M. Ju, H.M. Hsieh, Lar.N. Vassiljeva and Akulov (JX160062), and Xylaria longipes Nitschke (AY909016.1) at 95\% and 90\% thresholds, respectively, had the highest identity with the novel species of Xylaria. Analysis with the 'cluster_fast' algorithm at a 0.9 clustering threshold generated 218 clusters. All newly collected specimens clustered within a group containing 21 additional sequences, in which seven corresponded to X. bambusicola Y.M. Ju and J.D. Rogers (MF435163, KF381074, GU300088, EF026123, KU940160, JX256820, JX256818), one to X. grammica (Mont.) Mont. (KF312440), one to X. cornu-damae (Schwein.) Berk. (AF163031), and 12 to unidentified Xylaria spp. (KJ572198, KJ572199, KF430809, KJ958374, AB495009, AB512330, KF227849, MF045812, KF227839, AB512331, DQ322133, KT004562). Most of these 21 species were collected as endophytes in different plant species and countries. Unfortunately, no $28 \mathrm{~S}$ or RPB2 sequences of $X$. primorskensis were available in GenBank for phylogenetic analyses. However, a Fast-Minimum Evolution tree implemented in Blast of available ITS sequences showed that $X$. longipes and $X$. primorskensis are sister taxa, and together form a sister group to our new taxon. 
After the alignment process, matrix A consisted of 122 sequences and 3888 characters (1413 for the ITS, 1357 for the 28S, and 1118 for the RPB2), with 905 parsimony-informative sites. Matrix B had 3016 characters (541 for the ITS, 1357 for the 28S, and 1118 for the RPB2), and 754 parsimony-informative, and matrix C included 339 sequences with 2159 characters (1574 for the ITS, and 585 for the 28S), and 533 parsimony-informative sites. Phylogenetic analyses of matrix A showed that sequence data of all specimens collected in the cloud forest in central Veracruz, formed a monophyletic clade with the highest possible support values $(\mathrm{BS}=100, \mathrm{JK}=100, \mathrm{PP}=1.0$; Fig. 1). Matrix $\mathrm{B}$ had a $\mathrm{PP}$ value of 0.99 , and matrix C a JK value of 99 (topologies not shown). Our analyses recovered most clades obtained by U'Ren et al. (2016) and revealed that the novel species is nested within a small clade inside the "Xylaria PO clade" (U'Ren et al. 2016). Xylaria longipes (isolate CBS 148.73) was the sister taxon to the novel species with high support values $(\mathrm{BS}=89, \mathrm{JK}=98$, $\mathrm{PP}=0.98$ ). Xylaria allantoidea (Berk.) Fr. (isolate 94042903) is a sister to this clade, with support values of $\mathrm{BS}=98, \mathrm{JK}=100$, and $\mathrm{PP}=1.0$; and sister to these taxa was one small clade comprising two specimens of Xylaria regalis Cooke (isolates 920 and 92072001); one specimen of Xylaria digitata L. Grev. (isolate 919) and one of Xylaria acuta Peck (isolate AFTOL-ID 63). This last relationship; however, is uncertain due to low support values $(\mathrm{BS}=63, \mathrm{JK}=65, \mathrm{PP}=0.94)$. Analyses with matrix $\mathrm{B}$ recovered the same relationships among these species, but analyses with matrix $\mathrm{C}$ showed slight differences. Sister taxa to the novel species consisted of an unresolved moderately supported $(\mathrm{JK}=83, \mathrm{PP}=0.95)$ clade, containing the same specimen of Xylaria longipes (CBS 148.73, KU683868), a different specimen of Xylaria allantoidea (voucher MEL 2382670, KP013033), and Xylaria polymorpha (Pers.) Grev. (strain 305713, AB512310).

Taxonomy

Xylaria subtropicalis S. Chacón and F. Tapia, sp. nov. (Figs. 2A-F, 3G, H) 
TYPE:- MEXICO. Veracruz: Xalapa, Francisco Javier Clavijero Botanical Garden, 2.5 km old road Xalapa-Coatepec, $19^{\circ} 30^{\prime} 41^{\prime \prime} \mathrm{N}, 96^{\circ} 56^{\prime} 36^{\prime \prime} \mathrm{W}$, elevation 1320 m, 3 July 2015, S. Chacón, D. A. Aguilar and F. Tapia 8154 (holotype XAL).

GENBANK:-ITS = MG013556; 28S = MG013566; RPB2 = MG013547.

ETYMOLOGY:- The name reflects the climate and vegetation of the region where this species was first observed.

DiAGNOSIS:- Characterized by stromata erumpent through the bark of dead wood, penzigioid, cracked into minute beige to pale brown scales when young. Ascospores $23-28 \times 13-15 \mu \mathrm{m}$, ellipsoid, nearly equilateral, with a straight germ slit as long as the spore.

DESCRIPTION:- Stromata erumpent through the bark of dead wood, irregularly discoid to elongate, $0.4-1.7 \mathrm{~cm}$ diameter $\times 0.1-0.4 \mathrm{~cm}$ thick, flattened to pulvinate, then slightly sunken in the center, with conspicuous perithecial mounds; cracked into minute beige to pale brown scales that disappear with age; remaining carbonaceous surface, beige to brown; attached to substrate through a narrow, central connective, mostly multiperitheciate (up to 60 perithecia per stroma), with white and soft inner tissue. Perithecia globose to subglobose, $0.4-1.2 \mathrm{~mm}$ in diameter. Ostioles black, papillate, $0.1 \mathrm{~mm}$ broad, slightly raised. Asci with eight ascospores arranged in an uniseriate manner, hyaline, cylindrical, long-stipitate, $150-170 \times 12-14 \mu \mathrm{m}$ with the spore-bearing part being 100-130 $\mu \mathrm{m}$ long, with an inverted, hat-shaped, amyloid, apical ring of 3.5-4 × 5-6 $\mu \mathrm{m}$. Ascospores of 23-26 (-28) $\times 13-15 \mu \mathrm{m}$, dark brown to blackish brown, ellipsoid, nearly equilateral, with narrowly rounded ends sometimes pinched, with a straight germ slit spore-length.

HABITAT:- Gregarious on fallen twigs of Quercus sp.

DistRIBUTION:-Eastern Mexico, in a montane cloud forest, 1300-1460 m.

OTHER SPECIMENS EXAMINED:-Mexico. Veracruz State, municipality of Xalapa, Cerro Las Garzas, annexed to Molino de San Roque Ecological Park, $19^{\circ} 33^{\prime} 12^{\prime \prime}$ N, $96^{\circ} 56^{\prime} 17^{\prime \prime}$ W, elevation 1476 m, 28 August 2014, Chacón and F. Tapia 7793; Francisco Javier Clavijero 
Botanical Garden, 2.5 km old road Xalapa-Coatepec, $19^{\circ} 30^{\prime} 48^{\prime \prime} \mathrm{N}, 96^{\circ} 56^{\prime} 24^{\prime \prime} \mathrm{W}$, elevation 1350 m, 2 September 2011, S. Chacón and E. Utrera 6332; 8 May 2014, F. Tapia and S. Chacón 3043; 24 June 2014, F. Tapia 3096; 30 June 2014, F. Tapia and L. M. López-Guzmán 3104; 3 July 2015, F. Tapia, S. Chacón and D. A. Aguilar 3343; INECOL Cloud Forest Sanctuary, $2.5 \mathrm{~km}$ old road Xalapa-Coatepec, $19^{\circ} 30^{\prime} 41^{\prime \prime} \mathrm{N}, 96^{\circ} 56^{\prime} 36^{\prime \prime} \mathrm{W}$, elevation 1310 m, 14 October 2010, S. Chacón and E. Utrera 6090; 19 June 2013, S. Chacón and F. Tapia 2856; 29 April 2014, F. Tapia and S. Chacón 3031; 30 July 2014, S. Chacón, F. Tapia and L. M. López-Guzmán 7679; 17 September 2014, S. Chacón and F. Tapia 7896.

COMMENTARY:- Xylaria subtropicalis is recognized in the field by its penzigioid stromata erumpent through the bark of twigs of Quercus spp., the discoid form of the stromata that are slightly sunken in the center, and by the cracked surface that presents small scales from beige to pale brown in young specimens. Differences between $X$. subtropicalis and other Xylaria species are: The stromata being significantly erumpent, the size of the ascospores $23-28 \times$ 13-15 $\mu \mathrm{m}$, and a straight germ slit as long as the spore. There are other penzigioid Xylaria species with a resemblance to $X$. subtropicalis, such as $X$. albocinctoides, $X$. boergesenii, $X$. anisopleura, X. berteri, and X. discolor. Xylaria albocinctoides differs by having smaller stromata with a thin soft crust, $0.5-2 \mathrm{~mm}$ diameter $\times 0.5-0.8 \mathrm{~mm}$ thick, $\leq 10 \mathrm{~mm}$ long when confluent, and ascospores of $18-23 \times 10-12 \mu \mathrm{m}$, but with a straight germ slit that is similar to X. subtropicalis. Xylaria boergesenii also has a smaller stroma than X. subtropicalis, 0.5-3 mm diameter $\times 0.5-1 \mathrm{~mm}$ thickness, and ascospores measure of $19.5-26 \times 7-8.5 \mu \mathrm{m}$, but with a spiral to sigmoid germ slit. Xylaria anisopleura has subglobose to elongated or irregular and often moriform stromata and ascospores that measure 20-30 × 7.5-9.5 $\mu \mathrm{m}$, with a spiral or oblique germ slit that is shorter than the spore; whereas, $X$. berteri and $X$. discolor have a flattened or convex stroma, similar to the X. subtropicalis, but with ascospores less than 15 $\mu \mathrm{m}$ long (San Martín-Gonzalez and Rogers 1989; Ju et al. 2012; Tapia et al. 2017). 


\section{Discussion}

The species of Xylaria are difficult to identify due to their diverse and often convergent morphology. However, by combining morphological and molecular characteristics it is possible to recognize a new species. Our study focused on morphological and sequence data for a reliable characterization of ten collections of a novel Xylaria species. Our analyses convincingly proved that these new collections from a cloud forest correspond to a novel species, called Xylaria subtropicalis. Specimens consistently formed a strongly supported monophyletic group, independent from all other available sequence data from other species of Xylaria.

It is interesting to note that Xylaria subtropicalis and other penzigioid species (e.g., $X$. areolata (Berk. \& M.A. Curtis) Y.M. Ju and J.D. Rogers, X. berteri, X. cranioides, $X$. discolor, and X. frustulosa) are not grouped together, but scattered on different branches as was observed by U'Ren et al. (2016), despite $X$. berteri and $X$. discolor having a morphological resemblance to $X$. subtropicalis. Both specimens of $X$. discolor included in the analysis were monophyletic having X. lechatii Y.M. Ju, H.M. Hsieh, J.D. Rogers \& Fournier, another penzigioid species, as a sister taxon. Specimens of Xylaria berteri were also grouped with another penzigioid species (X. crozonensis P. Leroy \& Mornand); however, their relationship was paraphyletic.

According to the phylogenetic analyses, the sister taxa of the novel species are $X$. longipes and $X$. allantoidea while the Fast-Minimum Evolution tree showed that $X$. longipes and $X$. primorskensis are sister taxa, and together form a sister group to the novel species. These species considerably differ from $X$. subtropicalis by stipitate fruiting bodies, the form of fertile parts, and spore size, indicating that there have been numerous morphological transformations within the genus (Dennis 1956; Rogers 1984; San MartínGonzalez and Rogers 1989; Ju and Rogers 1999; Rogers et al. 2008). The only feature that $X$. primorskensis and $X$. subtropicalis appear to share is a long straight ascospore germ-slit (Ju et 
al. 2009). There are other factors that contribute to the discrepancies between the morphology and the molecular data. Studies performed at different levels within the family Xylariaceae have identified that disagreements between morphology-based classifications and molecular phylogenies could also be attributed to the lack of molecular data from many species including, type specimens, misidentified specimens and/or sequences in public databases, and the need for additional phylogenetic molecular markers. Therefore, our phylogeny, which is similar to many other phylogenies (Peršoh et al. 2009; Tang et al. 2009; Hsieh et al. 2010; Daranagama et al. 2015; Senanayake et al. 2015; U'Ren et al. 2016), reiterates the need for a thorough revision within the family.

Xylaria subtropicalis was collected on twigs of Quercus spp., which are found throughout the northern hemisphere down to the Equator in Asia, North America, Europe, and Africa. On the American continent, species of Quercus occur from Canada to Colombia (Nixon 2006). To our knowledge, $X$. subtropicalis is the first report of an erumpent species growing through the twig bark of oak trees. The wide range of natural distribution of the genus Quercus could also suggest that $X$. subtropicalis has a more extensive distribution. The novel species of Xylariaceae that was collected in a patch of cloud forest appears to be only a small fraction of the species of this family in Mexico. Consequently, further collections and sequence data are required for a better comprehension of its diversity in tropical countries.

\section{Acknowledgments}

This research was supported by the Instituto de Ecologia, A.C. through the projects: Patterns of Species Diversity in Urban Zones (grant 20035-30842) and the Integral Study 2013-2037 on the biodiversity of the Francisco Javier Clavijero Botanical Garden, with an emphasis on the Cloud Forest Sanctuary (grant 20035-30890). We express our gratitude to Fidel Tapia for his assistance in the study of the samples, and Yu Ming for corroborating the new species. We 
are also thankful to Elsa Utrera for assistance in processing tissue samples for sequencing, and to Manuel Hernandez for editing the illustrations. Our gratitude is also extended to the Editor, Associate Editor, and two anonymous reviewers for improving our manuscript.

\section{References}

Altekar, G., Dwarkadas, S., Huelsenbeck, J.P., and Ronquist, F. 2004. Parallel Metropolis coupled Markov chain Monte Carlo for Bayesian phylogenetic inference. Bioinformatics, 20: 407-415. doi.org/10.1093/bioinformatics/btg427

Boc, A., Diallo, A.B., and Makarenkov, V. 2012. T-REX: a web server for inferring, validating and visualizing phylogenetic trees and networks. Nucleic Acids Res. 40 (Web Server issue): W573-579. doi.org/10.1093/nar/gks485

Chacón, S., and Guzmán, G. 1983. Penzigia conostoma y Penzigia enteroleuca (Ascomycetes, Pyrenomycetes, Sphaeriales) en México. Bol. Soc. Mex.Micol. 18: 2932.

Chacón, S., and Medel, R. 1993. Los hongos (principalmente macromicetos) registrados en el bosque mesófilo de montaña de México. En Contribuciones micológicas en homenaje al Biólogo José Castillo Tovar, por su labor en pro de la micología mexicana. Número Especial 13. Editado por J. Marmolejo y F. Garza-Ocañas. Facultad de Ciencias Forestales, Universidad Autónoma de Nuevo León, Méx. pp. 61-110

Challenger, A. 1998. Utilización y conservación de los ecosistemas terrestres de México. Pasado, presente y futuro. México, D.F: Comisión Nacional para el Conocimiento y Uso de la Biodiversidad, Instituto de Biología, Universidad Nacional Autónoma de México y Agrupación Sierra Madre.

Daranagama, D.A., Camporesi, E., Tian, Q., Liu, X., Chamyuang, S., Stadler, M., and Hyde, K.D. 2015. Anthostomella is polyphyletic comprising several genera in Xylariaceae. 
Fungal Divers. 73: 203-238.

Del Olmo-Ruiz, M., García-Sandoval, R., Alcántara-Ayala, O., Véliz, M., and Luna-Vega, I. 2017. Current knowledge of fungi from Neotropical montane cloud forests: distributional patterns and composition. Biodivers. Conserv. 26: 1-24. doi.org/10.1007/s10531-017-1337-5

Dennis, R.W.G. 1956. Some Xylarias of Tropical America. Kew Bull. 11: 401-444.

Edgar, R.C. 2010. Search and clustering orders of magnitude faster than BLAST. Bioinformatics, 26: 2460-2461. doi.org/10.1093/bioinformatics/btq461

Goloboff, P.A. 1994. Nona. 1.5.1. ed. New York: American Museum of Natural History.

González-Espinosa, M., Meave, J.A., Ramírez-Marcial, N., Toledo-Aceves, T., LoreaHernández, F.G., and Ibarra-Manríquez, G. 2012. Los bosques de niebla de México: conservación y restauración de su componente arbóreo. Ecosistemas, 21: 36-52. Available from http://www.redalyc.org/articulo.oa?id=54026849004

Hall, T.A. 1999. BioEdit: a user-friendly biological sequence alignment analysis program for Windows 95/98/NT. Nucleic Acids Symp. Ser. 41: 95-98.

Hsieh, H-M., Lin, C-R., Fang, M-J., Rogers, J.D., Fournier, J., Lechat, C., and Ju, Y-M. 2010. Phylogenetic status of Xylaria subgenus Pseudoxylaria among taxa of the subfamily Xylarioideae (Xylariaceae) and phylogeny of the taxa involved in the subfamily. Mol. Phylogenet. Evol. 54: 957-969. doi.org/10.1016/j.ympev.2009.12.015

Huelsenbeck, J.P., and Ronquist, F. 2001. MRBAYES: Bayesian inference of phylogenetic trees. Bioinformatics, 17: 754-755. doi.org/10.1093/bioinformatics/17.8.754 
Ju, Y-M., and Rogers, J.D. 1999. The Xylariaceae of Taiwan (excluding Anthostomella). Mycotaxon, 73: 343-440.

Ju, Y-M., and Rogers, J.D. 2001. Xylaria cranioides and Poronia pileiformis and their anamorphs in culture, and implications for the status of Penzigia. Mycol. Res. 105: 1134-1136._doi.org/10.1016/S0953-7562(08)61977-2

Ju, Y-M., Hsieh, H-M., Vasilyeva, L., and Akulov, A. 2009. Three new Xylaria species from Russian Far East. Mycologia, 101: 548-553. doi.org/10.3852/08-188

Ju, Y-M., Hsieh, H-M., Rogers, J.D., Fournier, J., Jaklitsch, W.M., and Courtecuisse, R. 2012. New and interesting penzigioid Xylaria species with small, soft stromata. Mycologia, 104: 766-776. doi.org/10.3852/11-313

Katoh, K., and Standley, D.M. 2013. MAFFT multiple sequence alignment software version 7: improvements in performance and usability. Mol. Biol. Evol. 30: 772-780. doi.org/10.1093/molbev/mst010

Kirk, P.M., Cannon, P.F., Minter, D.W., and Stalpers, J.A. 2008. Ainsworth and Bisby's dictionary of the Fungi (10th ed). CAB International, Wallingford.

Lanfear, R., Frandsen, P.B., Wright, A.M., Senfeld, T., and Calcott, B. 2017. PartitionFinder 2: new methods for selecting partitioned models of evolution for molecular and morphological phylogenetic analyses. Mol. Biol. Evol. 34: 772-773. doi.org/10.1093/molbev/msw260

Lee, J.S., Ko, K.S., and Jung, H.S. 2000. Phylogenetic analysis of Xylaria based on nuclear ribosomal ITS1-5. 8S-ITS2 sequences. FEMS Microbiol. Lett. 187: 89-93. doi.org/10.1111/j.1574-6968.2000.tb09142.x 
Liu, Y.J., Whelen, S., and Hall, B.D. 1999. Phylogenetic relationships among ascomycetes: evidence from an RNA polymerse II subunit. Mol. Biol. Evol. 16: 1799-1808. doi.org/10.1093/oxfordjournals.molbev.a026092

Matheny, P.B. 2005. Improving phylogenetic inference of mushrooms with RPB1 and RPB2 nucleotide sequences (Inocybe, Agaricales). Mol. Biol. Evol. 35: 1-20. doi.org/10.1016/j.ympev.2004.11.014

Medel, R. 2007. Ascomycetes citados de México IV: 1996-2006. Rev. Mex. Micol. 25: 6976.

Medel, R. 2013. Hongos ascomicetos del bosque mesófilo de montaña en México. Acta Bot. Mex. 105: 87-106. doi.org/10.21829/abm105.2013.224

Medel, R., Castillo, R., and Guzmán, G. 2008. Las especies de Xylaria (Ascomycota, Xylariaceae) conocidas de Veracruz, México y discusión de nuevos registros. Rev. Mex. Micol. 28: 101-118.

Muñiz-Castro, M.A., Williams-Linera, G., and Reyes, J.M. 2006. Distance effect from cloud forest fragments on plant community structure in abandoned pastures in Veracruz, Mexico. J. Trop. Ecol. 22: 431-440. doi.org/10.1017/S0266467406003221

Nixon, K.C. 1999. The Parsimony Ratchet, a new method for rapid parsimony analysis. Cladistics, 15: 407-414. doi.org/10.1111/j.1096-0031.1999.tb00277.x

Nixon, K.C. 2006. Global and neotropical distribution and diversity of oak (genus Quercus) and oak forests. In Ecology and conservation of neotropical montane oak forests. Edited by M. Kappelle. Springer-Verlag, Berlin, Heidelberg. pp. 1-5.

Peršoh, D., Melcher, M., Graf, K., Fournier, J., Stadler, M., and Rambold, G. 2009. Molecular and morphological evidence for the delimitation of Xylaria hypoxylon. Mycologia, 
101: 256-268. doi.org/10.3852/08-108

Reeb, V., Lutzoni, F., and Roux, C. 2004. Contribution of RPB2 to multilocus phylogenetic studies of the euascomycetes (Pezizomycotina, Fungi) with special emphasis on the lichen-forming Acarosporaceae and evolution of polyspory. Mol. Phylogenet. Evol. 32: 1036-1060. doi.org/10.1016/j.ympev.2004.04.012

Rogers, J.D. 1984. Xylaria cubensis and its anamorph Xylocoremium flabelliforme, Xylaria allantoidea, and Xylaria poitei in continental United States. Mycologia, 76: 912-923.

Rogers, J.D. 1985. Anamorphs of Xylaria: Taxonomic considerations. Sydowia, Annales Mycologici Ser. II, 38: 255-262.

Rogers, J.D., Miller, A.N., and Vasilyeva, L.N. 2008. Pyrenomycetes of the Great Smoky Mountains National Park. VI. Kretzschmaria, Nemania, Rosellinia and Xylaria (Xylariaceae). Fungal Divers. 29: 107-116.

Ronquist, F., and Huelsenbeck, J.P. 2003. MrBayes 3: Bayesian phylogenetic inference under mixed models. Bioinformatics, 19: 1572-1574. doi.org/10.1093/bioinformatics/btg180

Rzedowski, J. 1978. Vegetación de México. Limusa, México D.F.

Rzedowski, J. 1996. Análisis preliminar de la flora vascular del bosque mesófilo de montaña en México. Acta Bot. Mex. 35: 25-44.

San Martín, F., and Rogers, J.D. 1995. Notas sobre la historia, relaciones de hospedante y distribución del género Xylaria (Pyrenomycetes, Sphaeriales) en México. Acta Bot. Mex. 30: 21-40.

San Martín-Gonzalez, F., and Rogers, J.D. 1989. A preliminary account of Xylaria of Mexico. Mycotaxon, 34: 283-373. 
Senanayake, I.C., Maharachchikumbura, S.S.N., Hyde, K.D., Bhat, J.D., Jones, E.B.G., McKenzie, E.H.C., Dai, D.-Q., Daranagama, D.A., Dayarathne, M.C., Goonasekara, I.D., Norphanphoun, C., Li, Q., Liu, X.Z., Bahkali, A.H., Kang, J.C., Wang, Y., Wen, T. C., Wendt, L., Xu, J.C., and Camporesi, E. 2015. Towards unraveling relationships in Xylariomycetidae (Sordariomycetes). Fungal Divers. 73: 73-144.

Stamatakis, A. 2006. RAxML-VI-HPC: maximum likelihood-based phylogenetic analyses with thousands of taxa and mixed models. Bioinformatics, 22: 2688-2690. doi.org/10.1093/bioinformatics/bt1446

Stielow, J.B., Lévesque, C.A., Seifert, K.A., Meyer, W., Irinyi, L., Smits, D., Renfurm, R., Verkley, G.J.M., Groenewald, M., Chaduli, D., Lomascolo, A., Welti, S., LesageMeessen L., Favel, A., Al-Hatmi, A.M.S., Damm, U., Yilmaz, N., Houbraken, J., Lombard, L., Quaedvlieg, W., Binder, M., Vaas, L.A.I., Vu, D., Yurkov, A., Begerow, D., Roehl, O., Guerreiro, M., Fonseca, A., Samerpitak, K., Van Diepeningen, A.D., Dolatabadi, S., Moreno, L.F., Casaregola, S., Mallet, S., Jacques, N., Roscini, L., Egidi, E., Bizet, C., Garcia-Hermoso, D., Martín, M.P., Deng, S., Groenewald, J.Z., Boekhout, T., De Beer, Z.W., Barnes, I., Duong, T.A., Wingfield, M.J., De Hoog, G.S., Crous, P.W., Lewis, C.T., Hambleton, S., Moussa, T.A.A., Al-Zahrani, H.S., Almaghrabi, O.A., Louis-Seize, G., Assabgui, R., Mccormick, W., Omer, G., Dukik, K., Cardinali, G., Eberhardt, U., De Vries, M., and Robert, V. 2015. One fungus, which genes? Development and assessment of universal primers for potential secondary fungal DNA barcodes. Persoonia, 35: 242-263. doi.org/10.3767/003158515X689135

Tang, A.M.C., Jeewon, R., and Hyde, K.D. 2009. A re-evaluation of the evolutionary relationships within the Xylariaceae based on ribosomal and protein-coding gene sequences. Fungal Divers. 34: 127-155. 
Tapia, F., Ju, Y-M., Chacón, S., and Utrera-Barillas, E. 2017. Five penzigioid Xylaria species from Veracruz (Mexico). Mycotaxon, 132: 19-27. doi.org/10.5248/132.19

Toledo-Aceves, T., García-Franco, J.G., Willias-Linera, G., Macmillan, K., and GallardoHernández, C. 2014. Significance of remnant cloud forest fragments as reservoirs of tree and epiphytic bromeliad diversity. Trop. Conserv. Sci. 7: 230-243.

U'Ren, J.M., Miadlikowska, J., Zimmerman, N.B., Lutzoni, F., Stajich, J.E., and Arnold, A.E. 2016. Contributions of North American endophytes to the phylogeny, ecology, and taxonomy of Xylariaceae (Sordariomycetes, Ascomycota). Mol. Phylogenet. Evol. 98: 210-232. doi.org/10.1016/j.ympev.2016.02.010

Vilgalys, R., and Hester, M. 1990. Rapid genetic identification and mapping of enzymatically amplified ribosomal DNA from several Cryptococcus species. J. Bacteriol. 172: 42384246. doi.org/10.1128/jb.172.8.4238-4246.1990

White, T.J., Bruns, T., Lee, S., and Taylor, J. 1990. Amplification and direct sequencing of fungal ribosomal RNA genes for phylogenetics. In PCR Protocols: A guide to methods and applications. Edited by M.A. Innis, D.H. Gelfand, J.J. Sninsky, and T.J. White. Academic Press, New York. pp. 315-322 
Table 1. Collection numbers, localities, and GenBank accession numbers of Xylaria subtropicalis.

\begin{tabular}{|c|c|c|c|c|c|}
\hline \multirow[b]{2}{*}{$\begin{array}{l}\text { Collection } \\
\text { ID }\end{array}$} & \multirow[b]{2}{*}{ Voucher } & \multirow[b]{2}{*}{ Locality } & \multicolumn{3}{|c|}{ GenBank accession number } \\
\hline & & & ITS & $28 \mathrm{~S}$ & RPB2 \\
\hline $\mathrm{X} 1$ & $\begin{array}{l}\text { S. Chacón, D.A. } \\
\text { Aguilar and F. } \\
\text { Tapia } 8154 \\
\text { (holotype) }\end{array}$ & $\begin{array}{l}\text { Jardín } \\
\text { Botánico FJC }\end{array}$ & MG013556 & MG013566 & MG013547 \\
\hline $\mathrm{X} 3$ & $\begin{array}{l}\text { S. Chacón, F. } \\
\text { Tapia and M.L. } \\
\text { López-Guzmán } \\
7669\end{array}$ & $\begin{array}{l}\text { Santuario } \\
\text { Bosque de } \\
\text { Niebla }\end{array}$ & MG013559 & MG013574 & - \\
\hline $\mathrm{X} 4$ & $\begin{array}{l}\text { F. Tapia and S. } \\
\text { Chacón } 3031\end{array}$ & $\begin{array}{l}\text { Santuario } \\
\text { Bosque de } \\
\text { Niebla }\end{array}$ & MG013564 & MG013569 & MG013552 \\
\hline $\mathrm{X} 5$ & $\begin{array}{l}\text { S. Chacón and F. } \\
\text { Tapia } 7793\end{array}$ & $\begin{array}{l}\text { Molino San } \\
\text { Roque }\end{array}$ & MG013560 & MG013572 & MG013548 \\
\hline X6 & F. Tapia 3096 & $\begin{array}{l}\text { Santuario } \\
\text { Bosque de } \\
\text { Niebla }\end{array}$ & MG013561 & MG013573 & MG013549 \\
\hline $\mathrm{X} 7$ & $\begin{array}{l}\text { S. Chacón and F. } \\
\text { Tapia } 2856\end{array}$ & $\begin{array}{l}\text { Santuario } \\
\text { Bosque de } \\
\text { Niebla }\end{array}$ & MG013565 & MG013575 & MG013550 \\
\hline $\mathrm{X} 8$ & $\begin{array}{l}\text { Tapia F. and S. } \\
\text { Chacón } 3043\end{array}$ & $\begin{array}{l}\text { Jardín } \\
\text { Botánico FJC }\end{array}$ & MG013562 & MG013571 & MG013551 \\
\hline X9 & $\begin{array}{l}\text { S. Chacón and E. } \\
\text { Utrera } 6332\end{array}$ & $\begin{array}{l}\text { Jardín } \\
\text { Botánico FJC }\end{array}$ & MG013563 & MG013568 & MG013553 \\
\hline $\mathrm{X} 11$ & $\begin{array}{l}\text { F. Tapia, S. } \\
\text { Chacón and D.A. } \\
\text { Aguilar } 3343\end{array}$ & $\begin{array}{l}\text { Jardín } \\
\text { Botánico FJC }\end{array}$ & MG013557 & MG013567 & MG013555 \\
\hline $\mathrm{X} 12$ & $\begin{array}{l}\text { F. Tapia and L.M. } \\
\text { López-Guzmán } \\
3104\end{array}$ & $\begin{array}{l}\text { Jardín } \\
\text { Botánico FJC }\end{array}$ & MG013558 & MG013570 & MG013554 \\
\hline
\end{tabular}


Table 2. Primer sequences and PCR conditions applied for each gene employed to amplify DNA from specimens of the new species Xylaria subtropicalis.

\begin{tabular}{|c|c|c|c|c|}
\hline Gene & $\begin{array}{l}\text { Primer } \\
\text { name }\end{array}$ & Reference & Sequence $\left(5^{\prime}-3^{\prime}\right)$ & $\begin{array}{l}\text { Cycle } \\
\text { conditions } \\
\text { annealing/ } \\
\text { extension }\end{array}$ \\
\hline \multirow[b]{2}{*}{ ITS } & ITS1 & \multirow{2}{*}{$\begin{array}{l}\text { White et al. } \\
1990\end{array}$} & TCCGTAGGTGAACCTGCGG & $55 \mathrm{C}, 30 \mathrm{~s}$ \\
\hline & ITS4 & & TCCTCCGCTTATTGATATGC & $\begin{array}{l}72 \mathrm{C}, 1 \\
\min \end{array}$ \\
\hline \multirow[b]{2}{*}{$28 \mathrm{~S}$} & LR0R & \multirow{2}{*}{$\begin{array}{l}\text { Vilgalys and } \\
\text { Hester } 1990\end{array}$} & ACCCGCTGAACTTAAGC & $51 \mathrm{C}, 45 \mathrm{~s}$ \\
\hline & LR5 & & TCCTGAGGGAAACTTCG & $\begin{array}{l}72 \mathrm{C}, 1 \\
\min \end{array}$ \\
\hline \multirow{4}{*}{ RPB2 } & bRPB2-6F & \multirow{4}{*}{$\begin{array}{l}\text { Matheny } 2005 \\
\text { Reeb et al. } \\
2004 \\
\text { Liu et al. } 1999\end{array}$} & TGGGGYATGGNTTGYCCYGC & $60 \mathrm{C}, 1$ \\
\hline & $\begin{array}{l}\text { bRPB2- } \\
7.1 \mathrm{R}\end{array}$ & & CCCATRGCYTGYTTMCCCAT & $\begin{array}{l}\min \\
72 \mathrm{C}, 2 \\
\min \end{array}$ \\
\hline & $\begin{array}{l}\text { RPB2- } \\
980 F\end{array}$ & & TGYCCIGCIGARACICCHGARGG & $\begin{array}{l}52 \mathrm{C}, 1 \\
\min \end{array}$ \\
\hline & fRPB2-7cR & & CCCATRGCTTGYTTRCCCAT & $\begin{array}{l}72 \mathrm{C}, 2 \\
\min \end{array}$ \\
\hline
\end{tabular}


Fig. 1. Maximum likelihood phylogram based on concatenated sequence data showing positions of ten collections of Xylaria subtropicalis and close relatives. Supporting values above $70 \%$ for at least two metrics $(\mathrm{BS} / \mathrm{JK} / \mathrm{PP})$ are shown at the nodes. GenBank accession numbers for ITS, $28 \mathrm{~S}$ and RPB2 are included following taxon names. NA = not available.

Fig. 2. Macro- and microscopic morphology of Xylaria subtropicalis. A, B: Stromata on wood; arrows indicate young stromata. C: Stromata surface with ostioles (dark spots) and remnants of pale brown scales. D: Asci with ascospores as seen by light microscopy. E: Mature and immature ascospores; arrow points to the tip of an ascus with an apical, inverted hat-shape ring. F: Ascospore; arrow indicates the straight germline as long as the spore. Bars: $\mathrm{A}=5 \mathrm{~mm} ; \mathrm{B}, \mathrm{C}=3 \mathrm{~mm} ; \mathrm{D}=23 \mu \mathrm{m} ; \mathrm{E}=11 \mu \mathrm{m} ; \mathrm{F}=8.5 \mu \mathrm{m}$. Photographed by S. Chacón.

Fig. 3. Ascospores as seen by scanning electron microscopy. Bars: $\mathrm{G}=5 \mu \mathrm{m} ; \mathrm{H}=20 \mu \mathrm{m}$. Photographed by T. Laez. 
99/100/1.0_GU322464 NA GQ848347 Xylaria haemorrhoidalis isolate 89041207

GU324735 NA GQ848348 Xylaria globosa isolate 775

-170\% Ratany GU322462 NA GQ848345 Xylana cf glebulosa 431 (HAST, JPage 24 of 26

-19410.85 GU322459 NA GQ848342 Xylaria atrosphaerica isolate 9111121

86/99/10 GU322460 NA GQ848343 Xylaria polymorpha isolate 1012

100/100/1.0 $100 / 100 / 1.0$ GU324738 NA GQ848351 Xylaria telfairii isolate 90081901

100/100/10 GU324737 NA GQ848350 Xylaria telfairii isolate 421

GU324742 NA GQ848355 Xylaria cf. heliscus 88113010 (HAST)

99/ OU: GU324741 NA GQ848354 Xylaria intracolorata isolate 90080402

GU324739 NA GQ848352 Xylaria luteostromata var. macrospora isolate 508

Vylaria subtropicalis (X11)

Xylaria subtropicalis $(X 11$

Xylaria subtropicalis $(X 3)$

Xylaria subtropicalis $X$

Xylaria subtropicalis $\left(\mathrm{X}^{12}\right.$

Xylaria subtropicalis $\times 5$ (

Xylaria subtropicalis X8

Xylaria subtropicalis $(X 7)$

Xylaria subtropicalis $(X 7)$

$61098 \quad X y$ raria subtropicalis $X$

98/1011 KU683768 NA KU684280 Xylaria longipes isolate CBS 14873

GU324743 NA GQ848356 Xylaria allantoidea isolate 94042903

10 (110_GU322456 NA GQ848338 Xylaria digitata isolate 919

-775/ g7 - LQ491493 AY544676 DQ247797 Xylaria acuta isolate AFTOL-ID63

00/100/1.0,GU324744 NA GQ848357 Xylaria regalis isolate 92072001

GU324745 NA GQ848358 Xylaria regalis isolate 920

72/85/0.99 $100 / 10011 / 10.99$ NA NA GQ848364 Xylaria cubensis 477 (HAST, VLA)

GU373810 NA GQ848366 Xylaria cubensis isotate 515

GU373810 NA GQ848366 Xylaria cubensis isolate 51

GU324747 NA GQ848360 Xylaria laevis isolate 95072910

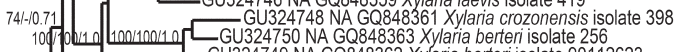

GU324749 NA GQ848362 Xylaria berteri isolate 90112623

100/10/10_ GU324752 NA GQ853019 Xylaria cf. castorea 91092303

78///999
84/90/0.98 r.GU322453 NA GQ848335 Xylaria feejeensis isolate 180

1001100110 - GU322454 NA GQ848336 Xylaria feejeensis isolate 92092013

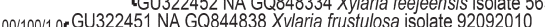

GU322450 NA GQ844837 Xylaria frustulosa isolate 92092010

U132446 NA GQ844833 Xylaria badia isolate 95070101

100/100110-GU322441 NA GQ844828 Xylaria lanthinovelutina isolate 553

10n/10n/1 o - GU322442 NA GQ844829 Xylaria culleniae isolate 189

95/-10.99 100/100/1.0 GU322438 NA GQ844824 Xylaria sp. 8 HMH-2010h

L GU322444 NA GQ844831 Xylaria curta isolate 494

GU322437 NA GQ844823 Xylaria apoda isolate 90080804

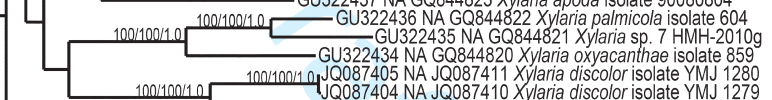

JQ087406 NA JQ087412 Xylaria lechatii isolate YMJ 780

GU322445 NA GQ844832 Xylaria phyllocharis isolate 528

100190.

$100 / 100 / 100$
GE026149 NA GQ844806 Xylaria venosula isolate 94080508

GU300089 NA GQ844803 Xylaria striata isolate 304

83/70/- KU940160 NA KU940183 Xylaria bambusicola strain MFLUCC 110606

EF026123 NA GQ844802 Xylaria bambusicola isolate 205

GU300088 NA GQ844801 Xylaria bambusicola isolate 162

- GU300075 NA GQ844785 Xylaria cranioides isolate 226

100/100/10 GU300092 NA GQ844808 Xylaria oligotoma isolate 784

GU300091 NA GQ844807 Xylaria venustula isolate 88113002

GU300080 NA GQ844793 Xylaria areolata isolate 543

GU300074 NA GQ844784 Xylaria tuberoides isolate 475

72-1073 GU300083 NA GQ844796 Xylaria amphithele isolate 529

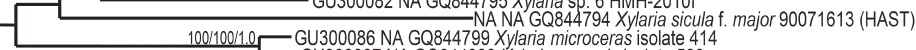

100/100/1.0 AF163035 NA DQ368652 Xylaria hypoxylon CBS 499.80

95/-11.0 821/10 KU683769 NA KU684286 Xylaria mali isolate CBS 385.35

GU300100 NA GQ844816 Xylaria papulis isolate 89021903

100 1001100110 - GU300101 NA GQ844817 Xylaria adscendens isolate 570

100/100/1.0 GU300098 NA GQ844814 Xylaria multiplex isolate 580

DQ631945 DQ840080 DQ631953 Xylaria sp. XT09003

$99 / 100 / 1.0$

d99/101 10/ 00/1.0

GU300096 NA GQ844812 Xylaria hypoxylon isolate 152

DQ491487 AY544648 DQ470878 Xylaria hypoxylon isolate AFTOL ID 51

GU300095 NA GQ844811 Xylaria hypoxylon isolate 95082001

J

GU300097 NA GQ844813 Xylaria grammica isolate 479

DQ631944 DQ840081 DQ631956 Xylaria sp. XT09009

86/98/0.98 GQ GU324756 NA GQ853029 Xylaria sp. $3 \mathrm{HMH}-2010 \mathrm{c}$

99/99/10 EU178738 NA GQ853028 Xylaria acuminatilongissima isolate 95060506

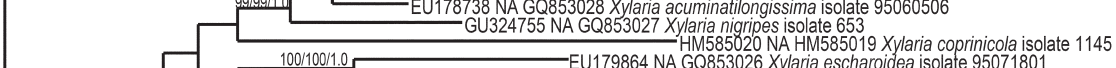
100/100/1.0 GU324754 NA GQ853025 Xylaria sp. 2 HMH-2010b

GU324754 NA GQ853025 Xylaria sp. 2 HMH-2010b
100/100/1.0_ EU179863 NA GQ53024 Xylaria cirrata isolate 95050402
G3/-10.99 GU24759 NA GQ853036 Xylaria sp. 1 HMH-2010a
GU324757 NA GQ853032 Xylaria sp. 4 HMH-2010d

99/92/1.0
99/97/1.0_EU179866 NA GQ853035 Xylaria intraflava isolate 95060509
EU179869 NA GQ853034 Xylaria ochraceostroma isolate 93073101

EU179862 NA GQ853023 Xylaria brunneovinosa isolate 95060505

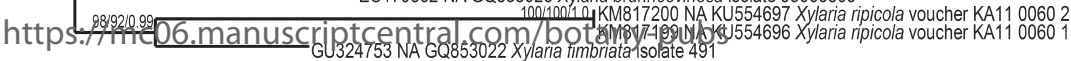

\section{0/100/1.0 GU324761 NA GQ853038 Podosordaria muli isolate 167}




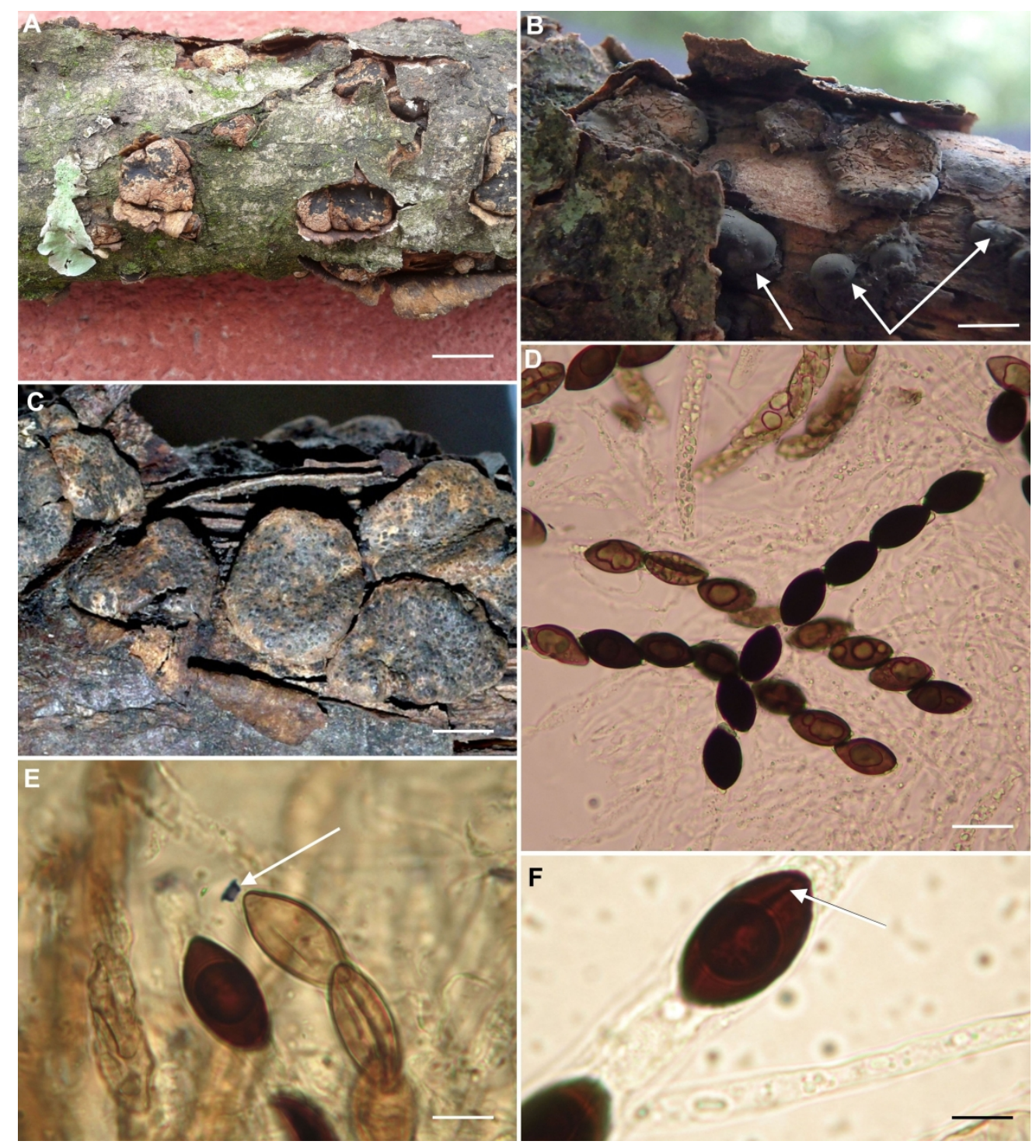

$167 \times 187 \mathrm{~mm}(600 \times 600 \mathrm{DPI})$ 

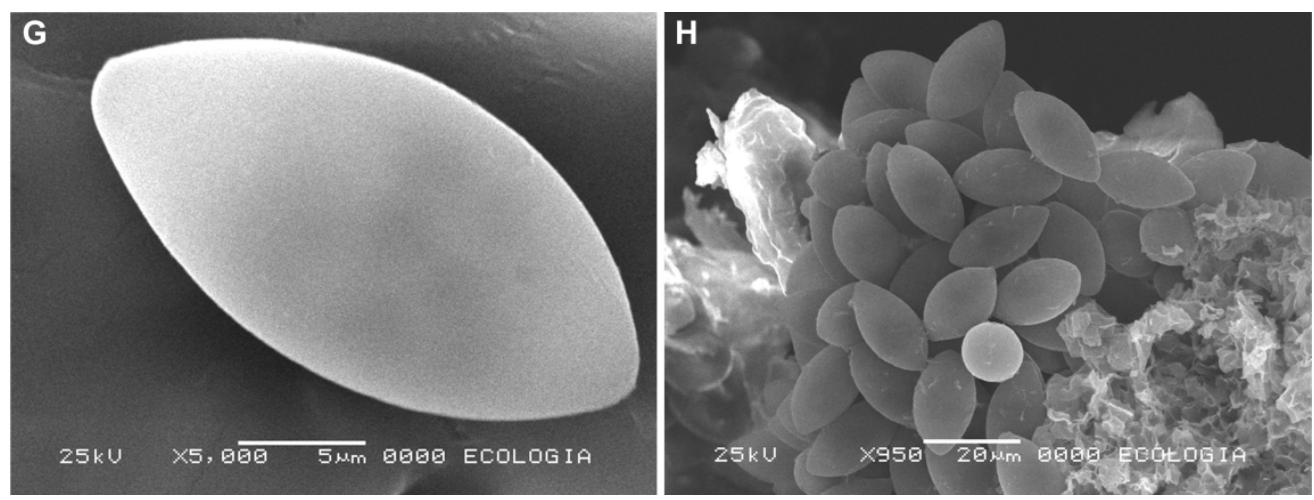

$169 \times 63 \mathrm{~mm}(600 \times 600 \mathrm{DPI})$

https://mc06.manuscriptcentral.com/botany-pubs 